\title{
Prenatal diagnosis of hereditary spastic paraplegia ${ }^{\dagger}$
}

\author{
Peter Hedera ${ }^{1}$, Jeffrey A. Williamson ${ }^{1}$, Shirley Rainier ${ }^{1}$, David Alvarado ${ }^{1}$, Turgut Tukel ${ }^{2}$, Memnune Apak ${ }^{2}$ and \\ John K. Fink ${ }^{1,3 *}$ \\ ${ }^{1}$ Department of Neurology, University of Michigan, Ann Arbor, MI, USA \\ ${ }^{2}$ Division of Medical Genetics, Institute of Child Health, University of Istanbul, Istanbul, Turkey \\ ${ }^{3}$ Geriatric Research Education Clinical Center, Ann Arbor Veteran's Affairs Medical Center, Ann Arbor, MI, USA
}

\begin{abstract}
Hereditary spastic paraplegia (HSP) is a degenerative neurologic disorder that causes progressive, often severe, spastic weakness in the legs. Autosomal dominant HSP is a highly penetrant, genetically heterogeneous disorder with loci present on chromosomes 2p21-24, 2q24-34, 8q23-24, 10q23.3-24, 12q13, 14q12-23, 15q11-14 and 19q13.1. We identified a large HSP kindred in which the disorder was tightly linked to chromosome 14q12-23. We tested chorionic villus DNA samples of two at-risk fetuses for inheritance of microsatellite polymorphisms flanking and within this locus that segregated with the disease in this family. Whereas samples from the first fetus showed inheritance of a haplotype segregating with the disease allele (indicating high risk of developing HSP), samples from the second fetus showed inheritance of a haplotype segregating with the normal allele (indicating low risk of developing HSP). This is the first report of prenatal testing for HSP. Published in 2001 by John Wiley \& Sons, Ltd.
\end{abstract}

KEY WORDS: paraplegia; spasticity; Strumpell-Lorrain

\section{INTRODUCTION}

Hereditary spastic paraplegia (HSP) is a group of clinically similar disorders characterized by insidiously progressive lower extremity spastic weakness (for reviews see Fink et al., 1996; Fink, 1997a,b; Fink and Hedera, 1999). Progressive gait disturbance begins in childhood, adolescence, or adulthood. Wheelchairs and other assistive devices are often necessary. Depending on the clinical subtype, urinary bladder disturbance and other neurologic deficits may occur. HSP is classified as 'uncomplicated' when the predominant disturbance is progressive lower extremity spastic weakness which may be accompanied by urinary bladder disturbance and impaired vibratatory sensation in the lower extremities. In uncomplicated or 'pure' HSP, upper extremity strength and dexterity remain normal. HSP is classified as 'complicated' when progressive spastic paraplegia is accompanied by additional neurologic deficits such as optic neuropathy, ataxia, amyotrophy or mental retardation. Specific treatments are not available to prevent, arrest, or reverse this progressively disabling disorder.

HSP may be transmitted as an autosomal recessive, autosomal dominant and X-linked disorder. Each of these HSP forms is genetically heterogeneous. Loci for autosomal dominant HSP exist on chromosome 2p2124, 2q24-34, 8q23-24, 10q23.3-24, 12q13, 14q12-23, 15q11-14 and 19q13.1 (Hazan et al., 1993; Hentati et al., 1994; Gispert et al., 1995; Hedera et al., 1999a,b; Reid et al., 1999; Seri et al., 1999; Fontaine et al., 2000; Reid et al., 2000). Uncomplicated HSP usually shows nearly complete, age-dependent penetrance. Nonetheless, dis-

*Correspondence to: J. K. Fink, Room 5214 CCGCB, $1500 \mathrm{E}$ Medical Center Drive, Ann Arbor, MI 48109-0940, USA. E-mail: jkfink@umich.edu

${ }^{\dagger}$ This article is a US Government work and is in the public domain in the USA. ease severity, rate of progression, age of symptom onset, and extent of functional disability may be variable within a given kindred; between families linked to the same locus; as well as between kindreds linked to different HSP loci (Fink and Hedera, 1999).

Among the 13 different genetic types of HSP (eight autosomal dominant, three autosomal recessive, and two X-linked loci), four HSP disease genes have been identified. Mutations in the proteolipidprotein gene (PLP) have been shown to cause both PelizeausMerzbacher disease and X-linked HSP (Kobayashi et al., 1994; Saugier-Veber et al., 1994; Cambi et al., 1995). Mutations in the L1CAM gene have been shown to cause a complicated form of X-linked spastic paraplegia (Jouet et al., 1994). Casari et al. (1998) showed that autosomal recessive HSP linked to chromosome 16 was due to mutations in a novel gene designated 'paraplegin' which encodes a mitochondrial metalloprotease. Recently, mutations in a novel gene ('spastin') were identified as causing the most common form of autosomal dominant HSP (linked to the SPG4 locus on chromosome 2p). Little is known about spastin's function although homology analysis predicts that spastin is a member of the AAA (ATPase Associated with diverse cellular Activities) class of of peptides and may be involved in assembly or function of nuclear protein complexes (Hazan et al., 1999). Genes for the remaining types of HSP, including autosomal dominant HSP linked to chromosome $14 \mathrm{q}$, are unknown.

Two couples in a large Turkish kindred with autosomal dominant HSP sought prenatal genetic testing. We evaluated the kindred, demonstrated that the disorder was tightly linked to chromosome 14q1223 , showed that the consultands were informative for linked microsatellite polymorphisms, and performed prenatal testing for two at-risk fetuses. 


\section{METHODS}

\section{Human subjects}

Informed consent was obtained and subjects participated as specified in the University of Michigan Institutional Review Board approved protocol. The portion of the kindred analyzed in this study (Figure 1) included 17 living affected subjects, six living unaffected subjects and four married-in spouses. Age-of-symptom onset was determined by interviewing the 17 affected subjects. Subjects were diagnosed as definitely affected with HSP or definitely unaffected according to published criteria (Fink et al., 1996).

\section{Genetic linkage to chromosome 14q}

Leukocyte DNA was extracted from peripheral blood samples from the 17 affected and eight unaffected subjects and the four married-in spouses. After ${ }^{32} \mathrm{P}$ kinase labeling one oligonucleotide primer, polymorphic microsatellite markers D14S75, D14S306, D14S600，D14S269，D14S746，D14S1031，D14S584 and D14S281 were amplified by the polymerase chain reaction (PCR) according to standard protocols: $100 \mu \mathrm{g}$ DNA, $1.5 \mathrm{mM} \mathrm{MgCl} 2,35$ cycles of $94^{\circ} \mathrm{C} 30 \mathrm{~s}$, $55^{\circ} \mathrm{C} 30 \mathrm{~s}, 72^{\circ} \mathrm{C} 30 \mathrm{~s}$. PCR products were separated by electrophoresis on $6 \%$ polyacrylamide gels and visualized by autoradiography. Two-point lod scores were calculated by MLINK using a disease allele frequency of 0.001 and a genetic penetrance of 0.9 .

\section{Analysis of chorionic villus DNA}

After obtaining informed consent, chorionic villus sampling was performed at 12 weeks in a 25 -year-old gravida two, para zero woman (subject III-6, Figure 1) and a 21-year-old primigravida (subject IV-3, Figure 1). DNA was extracted according to standard procedures. Microsatellite polymorphisms D14S75,
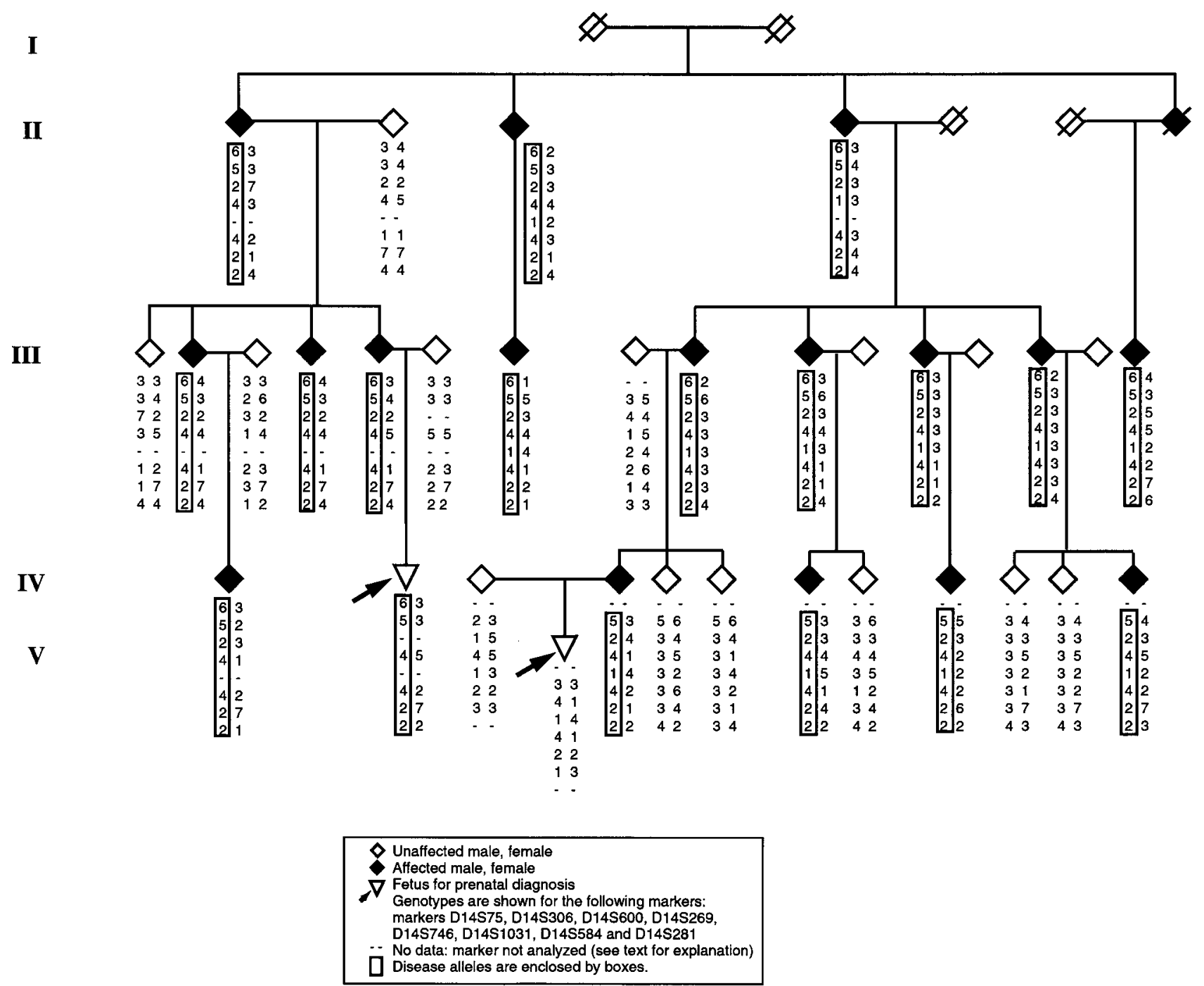

Figure 1-HSP kindred linked to chromosome 14q (SPG3). Gender identity is disguised to preserve anonymity. Genotypes are shown (in descending order) for microsatelite markers D14S75, D14S306, D14S600, D14S269, D14S746, D14S1031, D14S584 and D14S281. Haplotype segregating with the disease is boxed 
D14S306, D14S600, D14S269, D14 S 746, D14 S 1031, D14 S 584 and D14 S 281 were PCR amplified and analyzed as described above.

\section{RESULTS}

\section{Clinical features}

Each affected subject was the product of uneventful gestation, labor and delivery and attained developmental milestones normally. Each affected subject experienced onset of gait disturbance before age 3 years. Although many subjects experienced very little worsening, others reported that gait disturbance slowly increased, particularly in adolescence and adulthood. Neurologic examination of affected subjects showed relatively symmetrical, lower extremity spasticity, hyperreflexia, and weakness and extensor plantar responses. Disease severity was variable. While the majority of subjects experienced marked gait disturbance, several elderly affected subjects had only subtle gait impairment. Males and females were affected with equal frequency and severity. There was no evidence of genetic anticipation. Every affected subject had one affected parent. Observed genetic penetrance therefore was complete.

\section{Genetic analysis}

Two point lod scores (Table 1) reached a maximum of +5.59 for D14S584 at $\theta=0$. Two point lod scores for the other markesr (D14S75, D14S306, D14S600, D14S746, D14S269, D14S1031 and D14S281) were between +3.0 and +4.91 at $\theta=0$. These findings established conclusive linkage between the disorder and the HSP locus (SPG3) on chromosome 14q.

We analyzed haplotypes of 17 affected subjects and six unaffected subjects including the nuclear families seeking prenatal testing (parents III-5 and III-6 and their at-risk fetus IV-2; and parents IV-3 and IV-4 and their at-risk fetus V-1; Figure 1). The two couples seeking prenatal assessment were shown to be informative for markers (Figure 2) D14S75, D14S306, D14S269, D14S1031 and D14S281 (parents III-5 and III-6; Figure 1), and D14S306, D14S600, D14S269, D14S746, D14S1031 and D14S584 (parents IV-3 and IV-4; Figure 1) that segregated with the disorder in their family. The marker D14S746 was not mapped to

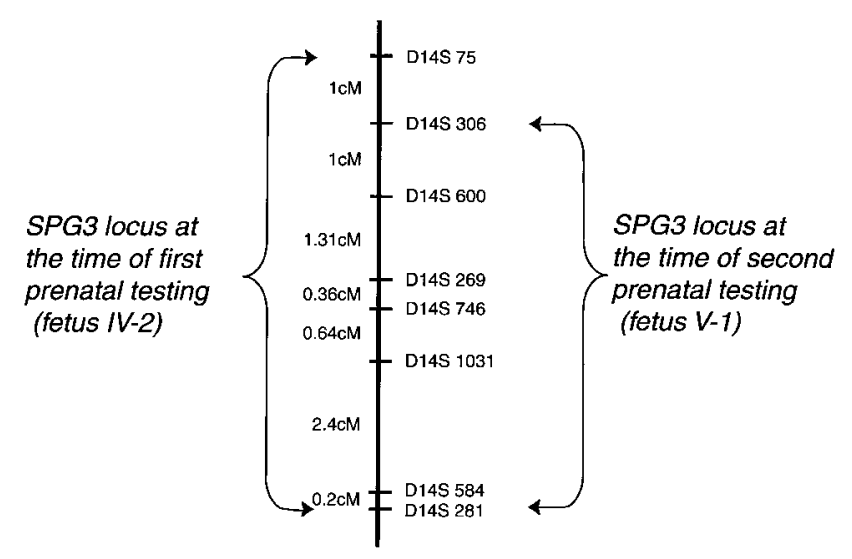

Figure 2-HSP locus (SPG3) on chromosome 14q12-23 illustrating location of microsatellite polymorphisms used for prenatal testing. Distances between markers are obtained from the Genome Database (http://www.gdb.org)

the SPG3 locus at the time of the first prenatal testing (at-risk fetus IV-2; Figure 1). We did not include marker D14S75 in the second prenatal testing (at-risk fetus V-1; Figure 1) because the locus had been reduced and this was no longer a flanking marker. Marker D14S600 was not analyzed in the first prenatal testing (at-risk fetus IV-2; Figure 1) and marker D14S281 was not analyzed in the second prenatal testing (at-risk fetus V-1; Figure 1) because one parent was uninformative for each of these markers (Figure 1).

At-risk fetus IV-2 inherited haplotypes that segregated with the disease for markers D14S75, D14S306, D14S269, D14S1031 and D14S281; markers D14S600 and D14S584 were uninformative. At-risk fetus V-1 inherited haplotypes for markers D14S306, D14S600, D14S269, D14S746, D14S1031 and D14S584 that segregated with the normal allele; marker D14S281 was uninformative.

\section{DISCUSSION}

In the first case (parents III-5 and III-6, fetus IV-2; Figure 1), analysis of chorionic villus DNA showed that the fetus inherited the disease allele for each microsatellite marker tested. Fetal inheritance of the normal allele would have required double simultaneous recombination between closely spaced markers, for which the combined probability is 0.0021 (see Figure 2

Table 1 - Results of two-point linkage analysis for microsatellite polymorphisms on chromosome 14q12-23

\begin{tabular}{llllllll}
\hline Marker & Penetrance & $\theta=0.001$ & $\theta=0.05$ & $\theta=0.1$ & $\theta=0.2$ & $\theta=0.3$ & $\theta=0.4$ \\
\hline D14S75 & 0.90 & 3.06 & 2.75 & 2.44 & 1.78 & 1.10 & 0.42 \\
D14S306 & 0.90 & 4.94 & 4.68 & 4.21 & 3.28 & 2.21 & 1.02 \\
D14600 & 0.90 & 3.47 & 3.16 & 2.83 & 2.10 & 1.27 & 0.43 \\
D14S269 & 0.90 & 3.21 & 2.92 & 2.63 & 1.97 & 1.22 & 0.45 \\
D14S746 & 0.90 & 3.07 & 2.74 & 2.41 & 1.71 & 0.97 & 0.29 \\
D14S1031 & 0.90 & 4.21 & 3.80 & 3.37 & 2.47 & 1.51 & 0.55 \\
D14S584 & 0.90 & 5.59 & 5.10 & 4.60 & 3.52 & 2.34 & 1.06 \\
D14S281 & 0.90 & 3.20 & 2.83 & 2.43 & 1.60 & 0.72 & 0.03 \\
\hline
\end{tabular}


for inter-marker distances). Conversely, the probability that the fetus inherited the HSP disease allele is 0.9979 .

In order to calculate disease risk conservatively, we assumed genetic penetrance to be 0.90 (even though observed genetic penetrance was 1.0). Given the chance that the fetus inherited the disease gene (0.9979) and assuming penetrance to be 0.9 , we calculated the probability that the fetus would be affected with HSP to be at least 0.898 . The family was informed and elected to terminate the pregnancy. Fetal tissues were not examined.

In the second case (parents IV-3 and IV-4, fetus at risk V-1; Figure 1), analysis of chorionic villus DNA showed that the fetus inherited the normal allele for each microsatellite marker tested. Fetal inheritance of the disease allele would have required double simultaneous recombination between closely spaced markers, for which the combined probability is 0.079 (see Figure 2 for inter-marker distances). Conversely, the probability that the fetus inherited the HSP normal allele is 0.921 .

The family was informed that the fetus would most likely inherit the normal allele and was thus at extremely low risk of inheriting HSP. They elected to continue the pregnancy. Follow-up information regarding the clinical status of the child is not yet available.

This first report of prenatal assessment of HSP risk illustrates important concerns regarding genetic counseling of HSP. First, although genetic penetrance in this family (and other autosomal dominant HSP kindreds) is very high, disease severity varies significantly. Although the majority of affected subjects in this kindred had moderate to severe spastic displegia, several adult subjects had only subtle gait disturbance that was not functionally disabling. Although the risk of inheriting the disease gene and genetic penetrance could be estimated, there were too few subjects to permit reliable estimates of the probability that the disease would be mild and not disabling instead of severe and functionally limiting. Second, although uncomplicated HSP (in this family and in general) is a lifelong, often disabling disorder, it does not shorten life span. Nonetheless, some HSP patients wish to conceive only if prenatal diagnosis is possible. Analysis of haplotypes of microsatellite polymorphisms that segregate with the disorder permits, for informative couples, prenatal risk assessment for dominantly inherited HSP linked to loci on chromosomes 8q, $10 \mathrm{q}, 12 \mathrm{q}, 14 \mathrm{q}, 15 \mathrm{q}$ and $19 \mathrm{q}$; recessively inherited HSP on chromosomes $8 \mathrm{p}$ and $15 \mathrm{q}$. Prenatal testing based on spastin gene analysis is applicable to approximately $45 \%$ of autosomal dominant HSP (Fink et al., 1996). Although quite rare, prenatal testing is also possible for autosomal recessive HSP due to paraplegin gene mutations (Casari et al., 1998), for X-linked HSP due to proteolipoprotein gene mutations (Cambi et al., 1995; Dube et al., 1997) and for X-linked HSP due to L1CAM gene mutations (Jouet et al., 1994). It is important to recognize, however, that each form (autosomal recessive, autosomal dominant and
X-linked) of uncomplicated HSP is genetically heterogeneous and that currently known loci do not account for all autosomal dominant HSP kindreds (Fink and Hedera, unpublished observations). Identifying these other loci will extend our ability to offer genetic counseling and prenatal diagnosis for this disorder and may reveal potential HSP candidate genes.

\section{ACKNOWLEDGEMENTS}

This research is supported by a Merit Review Award from the Department of Veterans Affairs and grants from the National Institute of Health (R01NS33645, R01NS38713, R01NS36177) and the Muscular Dystrophy Association (to J.K.F.). We gratefully acknowledge the expert secretarial assistance of Ms Lynette Girbach.

\section{REFERENCES}

Cambi F, Tartaglino L, Lublin FD, McCarren D. 1995. X-Linked pure familial spastic paraparesis: characterization of a large kindred with magnetic resonance imaging studies. Arch Neurol 52: 665-669.

Casari G, Fusco M, Ciarmatori S, et al. 1998. Spastic paraplegia and OXPHOS impairment caused by mutations in paraplegin, a nuclear-encoded mitochondrial metalloprotease. Cell 93: 973-983.

Dube M-P, Boutros M, Figlewicz DA, Rouleau GA. 1997. A new hereditary spastic paraplegia kindred maps to the proteolipid protein gene locus. Am J Hum Genet 61: 169

Fink JK. 1997a. Advances in hereditary spastic paraplegia. Curr Opin Neurol 10: 313-318.

Fink JK. 1997b. Hereditary spastic paraplegia. In The Encyclopedia of Neuroscience, Adelman G, Smith BH (eds). Elsevier Science: Amsterdam, 871-874

Fink JK, Hedera P. 1999. Hereditary spastic paraplegia: genetic heterogeneity and genotype-phenotype correlation. Semin Neurol 19: $301-310$.

Fink JK, Heiman-Patterson T, Bird T, et al. 1996. Hereditary spastic paraplegia: advances in genetic research. Neurology 46: 1507-1514.

Fontaine B, Davoine C-S, Durr A, et al. 2000. A new locus for autosomal dominant pure spastic paraplegia, on chromosome 2q24-q34. Am J Hum Genet 66: 702-707.

Gispert S, Santos N, Damen R, et al. 1995. Autosomal dominant familial spastic paraplegia: reduction of the FSP1 candidate region on chromosome $14 \mathrm{q}$ to $7 \mathrm{cM}$ and locus heterogeneity. $\mathrm{Am}$ J Hum Genet 56: 183-187.

Hazan J, Lamy C, Melki J, Munnich A, de Recondo J, Weissenbach J. 1993. Autosomal dominant familial spastic paraplegia is genetically heterogeneous and one locus maps to chromosome 14q. Nat Genet 5: 163-167.

Hazan J, Fonknechten N, Mavel D, et al. 1999. Spastin, a new AAA protein, is altered in the most frequent form of autosomal dominant spastic paraplegia. Nat Genet 23: 296-303.

Hedera P, DiMauro S, Bonilla E, Wald J, Eldevik OP, Fink JK. 1999a. Phenotypic analysis of autosomal dominant hereditary spastic paraplegia linked to chromosome 8q. Neurology 53: 44-50.

Hedera P, Rainier S, Alvarado D, et al. 1999b. Novel locus for autosomal dominant hereditary spastic paraplegia on chromosome 8q. Am J Hum Genet 64: 563-569.

Hentati A, Pericak-Vance M, Lennon F, et al. 1994. Linkage of a locus for autosomal dominant familial spastic paraplegia to chromosome 2p markers. Hum Mol Gen 3: 1867-1871.

Jouet M, Rosenthal A, Armstrong G, et al. 1994. X-linked spastic paraplegia (SPG1), MASA syndrome and X-linked hydrocephalus result from mutations in the L1 gene. Nat Genet 7: 402-407.

Kobayashi H, Hoffman EP, Marks HG. 1994. The rumpshaker mutation in spastic paraplegia. Nature Genet 7: 351-352.

Reid E, Dearlove AM, Rhodes M, Rubinsztein DC. 1999. A new 
locus for autosomal dominant 'pure' hereditary spastic paraplegia mapping to chromosome 12q13 and evidence for further genetic heterogeneity. Am J Hum Genet 65: 757-763.

Reid E, Dearlove AM, Osborn M, Rogers T, Rubinsztein DC. 2000. A locus for autosomal dominant 'pure' hereditary spastic paraplegia maps to chromosome 19q13. Am J Hum Genet 66: 728-732.
Saugier-Veber P, Munnich A, Bonneau D, et al. 1994. X-Linked spastic paraplegia and Pelizaeus-Merzbacher disease are allelic disorders at the proteolipid protein locus. Nat Genet 6: 257-262.

Seri M, Cusano R, Forabosco P, et al. 1999. Genetic mapping to 10q23.3-q24.2, in a large Italian pedigree, of a new syndrome showing bilateral cataracts, gastroesophageal reflux, and spastic paraparesis with amyotrophy. Am J Hum Genet 64: 586-593. 